\title{
Agenciamentos tecnosemiológicos e produção de subjetividade: contribuição para o debate sobre a trans-formação do sujeito na saúde
}

Techno-semiotics assemblage and subjectivity production: a discussion about the trans-formation of the subject in the health area

Ricardo Rodrigues Teixeira 1

\begin{abstract}
This article intends to raise a few points to be debated, about the transformation of the subject in the health area. It offers a conceptual frame that seems to be especially useful to explore the relationships between some "objective conditions" that we produce as social workers - and will be treated in terms of a techno-semiotic environment-, and the collective processes of subjectivity production. Key words Subjectivity, Technologies, Semiotics, Communication, Health
\end{abstract}

Resumo Este artigo se propõe a levantar algumas questões para o debate em torno da temática da transformação do sujeito no campo da saúde, oferecendo um quadro conceitual particularmente útil para explorar as relações entre algumas "condições objetivas" que produzimos como trabalhadores sociais, tratadas em termos de um meio tecnosemiológico, e os processos coletivos de produção da subjetividade.

Palavras-chave Subjetividade, Tecnologias, Semiótica, Comunicação, Saúde

\footnotetext{
1 Departamento de Medicina Preventiva

Centro de Saúde Escola

Samuel B. Pessoa,

Faculdade de Medicina

da USP. Av. Dr. Arnaldo,

455/2o andar - 01246-903

- São Paulo - SP

ricarte@usp.br
} 
Há liberdade para o homem todas as vezes que ele chegar, intelectualmente ou afetivamente, à mais intima relação que existe entre Sujeito e Objeto. Agostinho da Silva

Este texto foi originalmente elaborado para apoiar minha exposição oral no debate sobre "A trans-formação do sujeito na saúde", durante o VI Congresso Brasileiro de Saúde Coletiva (Salvador, de 28 de agosto a 1o de setembro de 2000). Apresento, a seguir, sua adaptação para um artigo, mas conservando seu caráter original de uma peça dirigida a levantar questões para o debate. Faço um pouco mais que isso: traço um quadro prévio, do qual pretendo fazer que derivem as autênticas questões para o debate.

Esse quadro prévio é, no fundo, a explicitação do modo como entendo estar substantivamente colocada a questão mais geral da trans-formação do sujeito. Ofereço, como é inevitável, um ponto de vista particular sobre o problema. Esclarecerei, rapidamente, de que lugar falo e a quem me dirijo e, desse modo, justifico um pouco a particularidade da minha contribuição.

A questão do sujeito interessa-me centralmente, mas minha aproximação do tema decorre, em grande medida, da posição que ocupo, como trabalhador e pesquisador, no amplo universo da saúde coletiva, que eu definiria como uma posição marcada por um intenso interesse pela problemática da inovação tecnológica (particularmente na área da prevenção e dos cuidados primários em saúde). Um intenso interesse pelos processos culturais (materiais e imateriais) em jogo (e, mais especificamente, pelas chamadas questões de comunicação e de educação em saúde). Dito de um modo ainda mais genérico, trata-se da problemática propriamente humana das técnicas, das diferentes culturas tecnológicas, o meu principal foco de preocupações. É dessa perspectiva, de quem transita pelo campo da saúde com tais preocupações, que foi se delineando um certo olhar e um certo modo de levar em conta a questão do sujeito, da sua formação, da sua trans-formação - o que se reflete, por exemplo, na busca de certas referências teóricas, no estudo de determinados autores, num mergulho em linhagens filosóficas bem específicas.

É claro que nossos pontos de vista e nossas falas também são, em outra boa medida, moldados "de fora", no entrechoque com outros discursos, no diálogo com outros pontos de vista, nas conversas - reais e imaginárias que mantemos com possíveis interlocutores. A presente intervenção, como mais um momento dessa conversa, é privilegiadamente dirigida aos "trabalhadores sociais" (cf. infra definição de Guattari \& Rolnik, 1986), particularmente àqueles que vêm atuando no campo da saúde coletiva, oferecendo-lhes uma possível “imagem para se pensar" (Deleuze \& Guattari, 1991), uma possível imagem para pensar como, com seu trabalho, com suas ações, participam da formação (que é sempre trans-formação) do sujeito.

Essas conversas são, igualmente, o diapasão em que afinamos as elevadas motivações ético-políticas que dominam o campo da saúde coletiva e que sustentam a compreensão mais amplamente partilhada, por essa comunidade de atores sociais e políticos, do sentido geral dessa trans-formação. Foi assim, por exemplo, que, num outro momento dessa infinita conversa, considerei como um desafio especialmente endereçado a este debate, a questão lançada por Carmem Teixeira (2000), no último boletim da Comissão Organizadora do Congresso: "como formar o sujeito da saúde coletiva?" Sua feliz colocação não apenas nos lembra da formidável tarefa formadora que cabe ao campo da saúde coletiva, mas ressalta, uma vez mais, que a idéia de trans-formação contém a idéia de formação. Na mesma linha de preocupação, coloca uma questão ainda mais fundamental: como criar "o espaço pedagógico capaz de estabelecer um olhar singular, inovador?" Não seria incorreto dizer que minha contribuição para o debate se restringe a procurar responder a essa única indagação, já que é possível se dizer que o meu principal esforço é o de examinar as reciprocidades que se estabelecem entre um dado "espaço pedagógico" e a constituição de um olhar, que é sempre de um sujeito e, oxalá, que possa ser singular e inovador... E poderia começar pela própria idéia de um "espaço pedagógico", que nos remete imediatamente a um conceito introduzido por um dos autores que mais tem iluminado a compreensão das questões tratadas a seguir: o filósofo francês Michel Serres (1995). Ele define a sociedade contemporânea precisamente como uma "sociedade pedagógica” (Teixeira \& Costa, 2000). Na concepção desse autor, todo "espaço social", todo "espaço de relações sociais" se constituiria e operaria um pouco como um "espaço pedagógico". Eu parto de concepções assemelhadas, que, 
ademais, nos aproximam da idéia grega antiga de paidéia (étimo da palavra "pedagogia"), que significava a educação das crianças e o ensino das técnicas, mas também a idéia de cultura, aquilo que definia a especificidade da cultura grega frente a todos os outros povos da Antigüidade, conforme nos ensina Werner Jaeger (1995), em seu célebre tratado sobre a "formação do homem grego". O modo como pretendo abordar o problema vai nessa direção, mas se serve de conceitos próprios, imanentes a um campo de problemas próprios, e que serão sumariamente apresentados a seguir.

Afinal, que contribuição pode dar para ampliar a compreensão da problemática do $s u$ jeito, alguém que se diz fundamentalmente interessado pela problemática das técnicas, uma vez que não se discute que as técnicas encontram-se situadas no pólo oposto ao dos sujeitos, isto é, no campo dos objetos?

Bem, de um modo simplificador, impreciso, mas válido como provocação introdutória, posso dizer que minha contribuição para o debate consiste exatamente em falar sobre as trans-formações do sujeito através das transformações nos objetos ou, mais amplamente, nas chamadas dimensões "objetais" da realidade... Para lograr meu intento, precisarei minimamente expor não uma teoria, porque não é a ocasião para isso, mas um breve mapa conceitual alternativo àquele que dispomos mais consensualmente para tratar dessas questões. Com ele, ficará logo visível que é a própria utilidade das noções tão familiares de sujeito e objeto que estará sendo, de uma certa forma, questionada. E isso, em favor de duas noções alternativas, que pretendo demonstrar serem mais adequadas para o tratamento das questões em foco: a noção de subjetividade, por um lado, e a noção de agenciamentos tecnosemiológicos, por outro. Procurarei ser tão claro quanto possível, tendo que ser ao mesmo tempo breve.

Comecemos pela noção de "sujeito". Ou melhor, por que não "sujeito"? Ou, ainda melhor, de que "sujeito" não tratarei?

Não tratarei aqui, antes de mais nada, do sujeito como algo do domínio de uma suposta natureza humana, conforme determinadas concepções oriundas da filosofia clássica e que marcaram toda uma tradição das ciências humanas. Do mesmo modo, não se trata do sujeito como a peça fundamental da teoria do conhecimento, conforme a invenção cartesiana, ainda que, devemos lembrar, Descartes ja- mais tratou da questão do sujeito propriamente dita. Ele fala no cogito, no pensamento, na consciência, na alma, na interioridade. Quem transformou o cogito cartesiano em sujeito foi o idealismo alemão: foi Kant, foi Fichte. No século XVII, "sujeito" não era um tema muito em voga. E não é que ainda não fosse um tema em voga, um tema que só apareceria mais tarde. Segundo os estudiosos de história da filosofia, a noção de sujeito faz sua primeira aparição ainda na Idade Média, quando Guilherme de Ockham introduziu a idéia de "direito subjetivo" - que, de resto, ainda não cessamos de explorar, como na idéia de um "sujeito de direitos", tão fundamental para as concepções contemporâneas de democracia (Chauí, 1997). Digo isso, apenas para nos precavermos contra o "novidadismo" e percebermos que o conceito tem história, marcada por irrupções e submersões e que a força que ganha neste final de século, ela mesma precisa ser compreendida.

Mas, enfim, no esquema básico instaurado por Descartes, filtrado pelo idealismo alemão e do qual pretendo me afastar, temos que: (1) o sujeito é sempre um indivíduo, um homem em carne e osso; (2) esse sujeito individual é sempre um sujeito universal, isto é, ainda que esse sujeito corresponda sempre a um homem com todas as suas propriedades particulares, é preciso que não corresponda a tal ou qual homem em particular, mas àquilo que no homem é idêntico em todos: a razão universal. Essa concepção de sujeito, não é demais lembrar, corresponde perfeitamente à cisão corpo/espírito, onde só o espírito é universal. Aqui, essa concepção será contestada em bloco. É do "sujeito transcendental” kantiano que pretendo me afastar e, sobretudo, não partilharei da preocupação extremada deste filósofo em separar aquilo que se refere ao sujeito daquilo que pertence ao objeto. Por outro lado, isso não quer dizer que saltarei automaticamente para o sujeito heideggeriano, o sujeito da filosofia pós- "giro lingüístico", esse sujeito que não é mais origem, mas um efeito secundário da linguagem, já em aberta afronta às concepções metafísicas de sujeito. Aqui, procurarei abandonar o terreno cultivado pela metafísica por outras vias. De um certo modo, e fazendo justiça a um predecessor de Heidegger, os meus caminhos seguem muito mais as pistas pioneiramente abertas na modernidade por aquele que, de fato, iniciou a demolição "a golpes de martelo" do edifício metafísico: Nietzsche (Pelbart, 1997). 
Assim, devo esclarecer, de maneira abreviada, que "sujeito" é esse que não é um indivíduo (e nem mesmo está centrado no indivíduo), que não é universal (e nem sequer constitui uma totalidade), que não se separa com precisão de seus "objetos" (e, de fato, estão variavelmente acoplados) e que nem se prende verticalmente a uma "ontologia" particular (e, de fato, se produz em processos multíplices e heterogêneos, que se dão em vários níveis e escalas diferentes). Para isso, para tratar desse outro "sujeito", darei preferência à noção de subjetividade.

Temos, então, em primeiro lugar, a subjetividade como algo não passível de totalização e nem centrada no indivíduo. Uma coisa é a individuação do corpo, outra é a multiplicidade dos processos que modelam a subjetividade. Nesse sentido, o indivíduo situa-se no entrecruzamento de múltiplos componentes de subjetividade, ou melhor, de múltiplos vetores de formação da subjetividade. Quando digo que a subjetividade é concebida como algo modelado, fabricado, produzido, por processos que não se dão no indivíduo, mas que $o$ atravessam, processos esses que podem ser ditos coletivos e sociais, não quero fazer desaparecer nem diminuir as dimensões individuais nos processos de subjetivação. Numa síntese, poderia dizer que a subjetividade é produzida tanto por instâncias individuais, quanto coletivas e institucionais. $\mathrm{O}$ mais importante, em todo caso, é essa idéia de algo produzido. Ela é inteiramente simétrica à refutação bergsoniana das teses da fenomenologia que definiam a consciência como "consciência de alguma coisa" e a sua proposição de que a consciência não é "consciência de", a consciência é "coisa" (Bergson, 1997); aqui também, não se trata apenas do sujeito como "sujeito de alguma coisa" ou "de uma ação", mas da subjetividade como "coisa" e "coisa produzida” (Deleuze, 1988; Foucault, 1990).

Quando, no princípio, me propus a tratar as transformações do "sujeito" a partir das transformações na esfera "objetiva", muitos podem ter imaginado que iria repetir os sistemas de determinação do marxismo clássico, do tipo "infra-estrutura material/supra-estrutura ideológica". Mas, já ao considerar a subjetividade sob o ângulo da produção, temos que ela recai, de maneira surpreendente, muito mais no campo da "infra-estrutura" do que da "supra-estrutura", onde seria classicamente situada. Além disso, como já disse, trata-se, aqui, de uma noção de subjetividade que não se prende verticalmente a qualquer "ontologia" particular, ela não reconhece instância alguma de determinação dominante que guie as outras instâncias segundo uma causalidade unívoca; os elementos que engendram a subjetividade não mantêm relações hierárquicas obrigatórias e definitivas, o que não quer dizer que não haja, a cada vez, em cada situação concreta, uma hierarquia de determinação ou, melhor dizendo, uma hierarquização dos fatores condicionantes dos modos possíveis de subjetivação. Trata-se, portanto, de uma hierarquização intensamente contextual, variando por completo no tempo e no espaço, jamais submetida a uma regra universal da psicogênese ou da antropogênese (Guattari, 1992). O que quer dizer que, no meu entender, qualquer "ciência da subjetividade" só pode funcionar no "regime" ou no "paradigma da complexidade"...

Um último ponto, que ainda considero essencial abordar nesta breve discussão sobre a noção de subjetividade, diz respeito à sua relação com o chamado "mundo objetivo". É claro que a contrapartida desse desmanche da visão de um "sujeito-substância ativo" de um lado só pode ser o desmantelamento da visão de um "mundo objetivo inerte" de outro. O esquema, que ora apresento, propõe uma visão da realidade como autênticos "encaixes fractais de subjetividade e objetividade" (Lévy, 1993). O deslocamento de uma visão a outra passa por compreender o quanto os chamados "objetos" são "sujeitos" ou, pelo menos, "atores", no mesmo movimento em que se busca compreender que a chamada subjetividade se compõe de múltiplas dimensões "objetais".

Ora, tudo aquilo que produz diferença em uma rede, em um sistema, enfim, no mundo, pode ser considerado um ator e todo ator se definirá a si mesmo pela diferença que produz. Dentro dessa definição, creio que seria até certo ponto desnecessário se estender demais demonstrando o quanto, por exemplo, objetos técnicos (estes de uma maneira particularmente flagrante) são efetivamente atores nos processos sociais em que estão envolvidos. O que me parece fundamental é discutir como "atuam" os objetos técnicos.

Mas, antes de passarmos a essa discussão sobre os objetos técnicos, ponto central e final da minha intervenção, abandonemos este registro excessivamente teórico e abstrato e saltemos para um plano de exemplos prosaicos, 
para que me faça melhor entender. Escolho, aliás, o exemplo mais popular possível para nós, brasileiros: o futebol.

O exemplo não é meu; aparentemente, seu autor é o já citado Serres (como tenho um conhecimento restrito de sua vastíssima produção, lamento desconhecer se este exemplo é, eventualmente, mencionado em alguma de suas obras) e nos é relatado por um de seus jovens discípulos, o também filósofo francês Pierre Lévy, que o definiu como um perfeito “teorema antropológico dos estádios" (Lévy, 2000). Ele opera por uma comparação polarizada entre o que eu, no presente contexto, chamaria uma "subjetividade das arquibancadas" e uma "subjetividade do gramado". Notem que não me refiro a uma "subjetividade dos torcedores" nem a uma "subjetividade dos jogadores”, o que seria uma generalização indevida. Mas há algo como uma produção coletiva de subjetividade fundamentalmente distinta nestes dois contextos, na total dependência de determinadas "condições objetivas". O exemplo tem a imensa virtude da simplicidade. Comecemos, observando o que se passa em cada caso.

Inicialmente, o que se passa nas arquibancadas? Os torcedores de um mesmo time, todos juntos, em uníssono, gritam ao mesmo tempo, as mesmas palavras de ordem. Neste caso, os atos individuais não se distinguem, nem se entrelaçam para fazer história.

O que é totalmente distinto do que se passa no gramado! Ali, cada jogador realiza ações nitidamente diferentes das dos outros, ainda que todas elas visem à coordenação, todas elas busquem se co-responder, busquem fazer sentido umas em relação às outras. Ali, cada ação intervém numa história coletiva, cada jogador com seus atos intervém diferentemente no curso de uma partida não decidida. Em campo, é preciso estar atento não apenas aos atos dos adversários, mas também - e isso é fundamental! - àquilo que se trama na sua própria equipe, para que os atos de seus companheiros não sejam em vão.

Enquanto isso, nas arquibancadas, os torcedores, evidentemente, não têm qualquer ação possível no jogo que, entretanto, os reúne ali, naquele instante. O campo lhes está inteiramente fora de alcance. Pode-se dizer que aquilo que os vincula no estádio é algo absolutamente transcendente em relação ao coletivo a que pertencem. Pode-se dizer que, neste caso, fazer-sociedade se resume a ser a favor ou contra, a amar alguns e a vaiar outros.
(Um parêntese: à pergunta - como criar um espaço pedagógico capaz de estabelecer um olhar singular e inovador? - poderia acrescer: como fazer-sociedade de maneira flexível, intensa e inventiva, sem fundar o coletivo no ódio do diferente ou sobre algum mecanismo vitimizador ou na referência a uma lei ou indivíduo transcendentes? Pois bem, voltemos aos gramados...)

Em campo, não basta detestar o adversário. É preciso estudá-lo, compreendê-lo, prevêlo, adivinhá-lo; é preciso, sobretudo, coordenar-se com os seus pares "em tempo real" (se me permitem o jargão "informático"); é preciso reagir fina e rapidamente "como um único homem" (não é assim que se diz no jargão futebolístico?) ...

A questão é: quem permite esta genial sinergia em campo?

Um objeto singular: a bola. Em campo, o que vincula e faz a mediação social não é algo transcendente, nem está fora de alcance. Pelo contrário, é algo que passa de mão em mão, ou melhor, de pé em pé. A viva unidade dos jogadores (que faz de cada equipe "um único homem") se organiza em torno de um "objeto", por assim dizer, imanente. Trata-se de um ser que circula entre todos; trata-se do "centro" da partida, mas um centro móvel e que designa, a cada momento, cada jogador, como o pivô transitório do time, este grupo inteligente (infinitamente mais inteligente como grupo, do que o grupo que temos reunido nas arquibancadas!), porque só tem a si mesmo como referência. A bola pode ser considerada o protótipo de um "objeto-vínculo", um objeto catalisador da subjetividade coletiva, de um certo tipo de subjetividade coletiva. Serres (1995) denomina este tipo de objeto de um "quaseobjeto". No contexto da presente intervenção, um tal objeto corresponde àquilo que venho chamando simplesmente de "objeto" e, segundo Lévy (2000), este "objeto" não é algo conhecido pelos animais...

Nesse sentido, os animais não têm "objeto". Eles podem ter uma presa que, de uma certa forma, é um "proto-objeto". E a caça suscita relações que podem ser de cooperação ou disputa, sendo, assim, uma espécie de operador primitivo da socialização. Mas o destino da presa é ser devorada, é ser incorporada, ser assimilada por esse "proto-sujeito". Felizmente para nós, um jogador só devora a bola, num sentido figurado.

Os animais também mantêm fortes relações com um território, demarcando-o com 
seus odores corporais ou com a extensão de seu canto, como no caso dos pássaros. Mas, neste caso também, o território ainda não é um "objeto", pois ele funciona como um elemento de apropriação e identificação exclusiva. Tampouco já vimos um jogador que pretendesse a apropriação exclusiva da bola (quando o faz, dizemos que é “fominha”, e só é perdoado dessa "falha" se fizer uma bela jogada individual; isso também se dá em certas atitudes "infantis”, mas que são situações que significam justamente o fim do jogo). Para que um objeto seja um "objeto" num sentido eminentemente humano, é preciso que passe de mão em mão, de sujeito a sujeito, e por isso a bola ilustra tão maravilhosamente bem este "objeto" (um outro protótipo deste tipo de "objeto" é quase impossível não lembrá-lo neste ponto - é o dinheiro, a moeda. E bastaria que todos a guardassem num cofre ou embaixo do colchão, isto é, bastaria a sua apropriação exclusiva e a interrupção da sua circulação, para por fim ao jogo, para fazer ruir toda a estrutura econômica).

Contudo, neste "objeto" não queremos apenas destacar a sua propriedade "hominizadora" e "socializante" em geral, mas enfatizar, sobretudo, que estas propriedades são da ordem da modalidade, isto é, que um "objeto-vínculo" particular não instaura nenhuma "humanidade" ou "sociedade humana" em geral, mas diferentes modos de "ser humano" e "fazer-sociedade".

A história da humanidade (começando pelo seu nascimento) pode ser contada como uma sucessão de surgimentos de "objetos" (começando, segundo os paleoantropólogos, pelo surgimento de um objeto técnico), cada um deles indissociáveis de uma particular dinâmica social e subjetiva, indissociáveis de um particular "regime de subjetividade" ou, melhor (para dar um acento marxiano!), de um particular "modo de produção de subjetividade". $\mathrm{Na}$ duração antropológica, objetos, sujeitos e sociedades se criam no mesmo movimento. Toda mudança social e trans-formação dos "sujeitos" implica a invenção de novos "objetos".

Para progressivamente irmos nos reaproximando da proposição inicial - de levar em conta fundamentalmente as dimensões tecnológicas do trabalho em saúde, para pensarmos o problema da trans-formação dos sujeitos -, consideremos agora o objeto por excelência da "hominização", da "socialização humana": o objeto técnico (Leroi-Gourhan, 1964). Ora, por isso mesmo, nenhuma definição coincide mais perfeitamente com a definição, que vimos construindo até aqui, de um "objeto" eminentemente humano, do que a definição mais geral de um objeto técnico: todo e qualquer artefato que passe de "mão em mão" durante os trabalhos e a vida coletiva, catalisando as relações sociais.

Esse "objeto" pode ser, por exemplo, um objeto referido a um "espaço de conhecimento", como uma "mensagem" ou uma "informação" (e não faltam esquemas teóricos para considerar os objetos técnicos em termos de "conhecimento", "mensagem" ou "informação" o exemplo mais banal é a cibernética, mas penso, em primeiro lugar, na obra do mais importante filósofo da técnica neste século: Gilbert Simondon [1989], sem falar na atualidade das ferramentas de informática em nossas vidas cotidianas, fazendo a mais espetacular demonstração prática da natureza informacional dos objetos técnicos; e também não nos faltam teorias para pensar todo "conhecimento", "mensagem” ou "informação" como artifícios, artefatos, como algo construído). Nesse terreno, também podemos identificar um certo tipo de desdobramento da polaridade observada no "teorema antropológico dos estádios". Os exemplos são sempre muito simples. Pensemos apenas em dois contextos técnicos distintos: num, a "mensagem" passa (é difundida) por um meio eletrônico de radiodifusão, como o rádio ou a televisão (as chamadas redes de broadcasting), noutro, passa (é distribuída) por um meio eletrônico onde produtores e exploradores das "mensagens" se confundem, como na internet (nas chamadas redes interativas ou de "hipertextualização"): a diferença em termos das socialidades que instauram e das subjetividades que induzem pode ser a diferença entre os torcedores impotentes e os jogadores com suas pluripotencialidades. É interessante notar, entretanto, que estes meios técnicos induzem, mas não determinam absolutamente as formas de socialidade ou subjetividade, já que tudo depende dos agenciamentos coletivos com que vêm se articular, já que raras vezes podemos levar em conta um meio técnico isolado e tudo funciona muito mais em termos de agenciamentos compósitos e redes técnicas heteróclitas. Dou exemplos: sabemos que o celular possibilitou uma transformação completa da socialidade imposta pelo rádio - do meio de difusão por excelência do fascismo nos anos 30 (McLuhan, 
1971), ao meio interativo produtor de uma espécie de inteligência coletiva na hora do rush nas grandes megalópoles engarrafadas -; por outro lado, sabemos que existem várias tentativas de captura da rede interativa pela "ideologia" do broadcasting introduzindo na rede mundial a chamada tecnologia push dos canais de web, ou ainda, as tentativas de introduzir sistemas de controle na rede, como tentam fazer os cookies e sistemas de data-mining, amaldiçoados pelos internautas libertários. São batalhas tecnopolíticas ainda não decididas! E existem ainda as falsas "interatividades", as coisas que mudam para não mudar, revelando a vocação regressiva de certos meios "de massa", quando por exemplo a interação proposta é do tipo "você decide": o que temos sempre é uma "subjetividade de arquibancada", do tipo sim ou não, contra ou a favor.

Notem que, até aqui, todas as considerações sobre os diferentes meios técnicos tomam como relativamente indiferente os conteúdos das "mensagens" (no melhor estilo mcluhaniano, do tipo "o meio é a mensagem”!). Para tentar esclarecer mais esse ponto, salto de exemplos referidos a um "espaço de conhecimento", "imaterial", para pelo menos um exemplo referido ao nosso "espaço físico" ou de existência "material": o espaço urbano (todos, em conjunto, constituindo os já mencionados "espaços pedagógicos”...).

Pensemos, por exemplo, num cortiço ou favela como espaços arquitetônico-urbanísticos e nos estados cognitivos e afetivos extremamente marcantes que induz em nós, visitantes e, ainda mais profundamente, naqueles que nela vivem. Contudo, em primeiro lugar, é preciso realizar um relativo esvaziamento de "conteúdos", principalmente daqueles que arrastam consigo uma forte carga de julgamentos, como é o caso de seus "conteúdos" de pobreza, miséria e precariedade, todos bastante reais. Mas é igualmente real - e é isso que eu gostaria de destacar agora - que a "espacialidade" própria dos cortiços e favelas está associada a formas de socialidade e subjetividade intensamente mais fraternas e solidárias, do mesmo modo que, nas ruas "tranqüilas" e desertas (como se fosse possível ficar tranqüilo num deserto) dos bairros ricos e condomínios fechados, com seus escassos encontros de vizinhos e a hostilidade ostensiva dos aparatos de segurança, germina o que eu chamaria de uma "subjetividade hobbesiana"... A arquiteta italiana, naturalizada brasileira, Lina Bo Bar- di, que com lucidez apaixonada tratou o espaço arquitetônico-urbanístico como um autêntico "espaço pedagógico" e fez de sua atividade construtora uma potente ferramenta de trans-formação e emancipação do homem, já havia compreendido tudo isso há mais de trinta anos e tentou tocar-nos com sua especial sensibilidade, antes que os antigos e pobres moradores do belo Pelourinho, em Salvador, fossem despejados. O que se despejou foi toda uma poderosa força de produção de subjetividade da qual permanecemos, muitos de nós, infinitamente distantes, alheios, alienados. O Pelourinho continua belo, mas sua beleza é outra e instauradora de outras subjetividades. A beleza do Pelourinho hoje tem algo da beleza de uma locação cinematográfica e parece mais relacionada a uma "subjetividade de flanneur", de turista, a um olhar superficial, de passagem. Pouco restou dos outros olhares que já habitaram os sobradões... O que não impede, é claro, que outros vetores de subjetivação se instalem, que novas subjetividades singulares, em permanente reinvenção, venham repovoá-los.

Mas, antes de encerrar, deveria ainda dar algum exemplo que tocasse a especificidade da nossa área, já que não somos nem arquitetos, nem trabalhadores da mídia ou jogadores de futebol (embora, talvez, sejamos também um pouco tudo isso). Mas, a grande questão, afinal, é exatamente esta: de que modo os objetos técnicos que pomos no mundo - com suas especificidades, tão impressionantemente marcantes, já que tocam o mais profundamente possível a nossa relação com o próprio corpo e o corpo alheio, com a dor, com o prazer, com o cuidado de si, com o cuidado do outro, com o sofrimento, com a felicidade, já que tocam o mais profundamente possível o âmago da própria vivência do "subjetivo" -, de que modo esses "objetos" que inventamos e disponibilizamos participam dos processos coletivos de produção de subjetividade? É esse que me parece ser, sem dúvida, o questionamento fundamental.

Creio já haver discutido, até aqui, o bastante a respeito desse "objeto", para que já possa iniciar a substituição desse conceito por outro, que, como prometi no início, me parece bem mais útil: à noção de "sujeito" contrapus a noção de subjetividade; à noção de "objeto", contraponho a noção, que esclarecerei agora, de agenciamentos tecnosemiológicos.

Já propus o abandono da idéia de um "objeto inerte”, uma vez que é possível perceber 
suas características de "ator" nos processos de que participa (definindo "ator" como tudo aquilo que produz diferenças no mundo e destacando esta propriedade, especialmente, nos objetos técnicos).

Ora, a idéia de agenciamento, em primeiro lugar, afirma esse seu caráter "agente" nos processos coletivos de produção de subjetividade, retira-os de uma dimensão de "exterioridade inerte", na qual estão habitualmente lançados. Em segundo lugar, designá-los por essa fusão semântica de técnicas e signos, já insinua uma pretendida unificação das dimensões "objetais" (isto é, das dimensões que se "obstam” à nossa consciência). Numa metáfora ecológica, poderíamos falar em meio tecnosemiológico. Não poderei desenvolver extensamente essa idéia, no momento, mas espero deixá-la implicitamente clara no que exporei a seguir. O que pomos efetivamente no mundo como objetos técnicos não são meramente tecnologias materiais, mas grandes sistemas compostos e complexos, indistintos e indissociáveis de técnicas e signos.

O que nos importa, então, é examinar de que maneira se acopla a idéia de produção de subjetividade à idéia de um meio tecnosemiológico (Maturana \& Varela, 1998). É nessa direção que venho procurando estudar estes últimos, os diferentes meios tecnosemiológicos; para isso, é importante uma compreensão, ao mesmo tempo, ampla e minuciosa da problemática das técnicas. De fato, tem sido de grande valia considerá-las num plano que pode ser dito "microfísico", isto é, num plano em que o que se leva em conta são suas características de interface, de uma operadora da "passagem": num plano em que são suas propriedades de "condução" as que primordialmente interessam. Tenho assumido como tarefa fundamental realizar uma espécie de "microfísica das passagens", reconhecer as moleculações que se processam neste nível e seus efeitos sobre os modos de produção de subjetividade. É por aí que chego a conceber que diferentes "modelos tecnológicos" possam ser vistos como diferentes políticas de interfaces, cada qual dando expressão a distintas poéticas sociais. Acho essencial que, para além de toda consideração sobre sua "eficácia", um dado "modelo tecnológico" seja, sobretudo, apreciado e avaliado em termos da poética social que propõe e carrega.

Quando introduzo o conceito de interface para realizar a análise "microfísica" do meio tecnosemiológico, chegando ao conceito com- posto de interfaces tecnosemiológicas, permito que nossa reflexão se beneficie das explorações de Lévy (1993) sobre aquele conceito. E quais são suas idéias básicas?

A noção de interface, antes de mais nada, remete às operações de passagem entre dois "elementos" heterogêneos e que incluem os transportes, transmissões, traduções, transformações, que se dão no encontro, contato, comunicação, entre esses dois "elementos". A interface pode ser definida como a "operadora da passagem".

Dentro dessa definição, a interface é concebida como uma realidade da ordem do molecular. Já os dispositivos aos quais pretendo estender este conceito são quase todos da ordem do molar, isto é, compreendem estruturas compostas e complexas que operam, na realidade, como uma rede de interfaces. Todas as técnicas, por exemplo, podem ser analisadas em redes de interfaces. Armas, ferramentas, diferentes máquinas, como os dispositivos de inscrição ou de transmissão, são concebidos precisamente para se imbricarem o mais intimamente possível com módulos cognitivos, circuitos sensoriomotores, porções de anatomia humana e outros artefatos em múltiplos agenciamentos de trabalho, de guerra ou comunicação (Lévy, 1993).

Mas não só artefatos são interfaces. Tudo que é da ordem da tradução, do contato, da articulação, pode ser dito uma interface (por exemplo, a passagem de um código a outro, um momento de um processo, um fragmento de atividade etc.)

E quais são as características mais fundamentais do "funcionamento" de uma interface?

Toda interface condiciona o modo da captura da "informação" que é oferecida aos atores da "comunicação" que ela torna possível. Ela abre ou fecha e, sobretudo, ela orienta os domínios de ação e significação (emoções e linguagem), as utilizações possíveis daquele "meio" que "interfaceia". Em outras palavras, a interface define a dimensão pragmática do "encontro", isto é, aquilo que pode ser feito com a interface, aquilo que pode ser negociado nas fronteiras, no encontro: ... de um ponto de vista pragmático, todas (as interfaces) são condutores deformantes em um coletivo heterogêneo, cosmopolita. Os mais diversos agenciamentos compósitos podem interfacear, ou seja, articular, transportar, difratar, interpretar, desviar, transpor, traduzir, trair, amortecer, amplificar, filtrar, inscrever, conservar, conduzir, transmitir ou parasitar... (Lévy, 1993). 
Dessa perspectiva, podemos dizer que quase tudo é interfaceamento, "porque quase nada fala a mesma língua nem segue a mesma norma", nenhuma "mensagem" se transmite tal qual por um condutor considerado neutro, porque atravessa descontinuidades que a transformam. Jamais, por exemplo, uma "demanda de saúde" se apresenta a um "serviço de saúde", num encontro assistencial, sem ser afetada pela "forma desta relação", sem que a captura dessa "informação" (a demanda de saúde) já não signifique uma metamorfose no seu conteúdo...

E quais as vantagens de se pensar as dimensões "objetais", os agenciamentos tecnosemiológicos, como interfaces?

Primeiramente, de modo simétrico ao próprio conceito de produção de subjetividade acima apresentado, essa noção de interface também quebra com a tendência do pensamento de essencializar as realidades e concebe suas dimensões "objetais" como uma multiplicidade conectada. Além disso, ela afasta a ilusão de que as "informações" possam mudar de suporte conservando a sua identidade e faz perceber que o que chamamos de "informação" é, em grande medida, o efeito das interfaces, dos suportes.

Seguindo essa direção geral, a proposta é refletir sobre os possíveis efeitos de subjetividade que se produzem nas redes de interfaces. E acompanhando as teses de Lévy, também penso que esta é fundamentalmente uma reflexão ético-política, já que uma rede de agenciamentos tecnosemiológicos, isto é, uma rede de interface, dada essa sua incidência sobre a dinâmica subjetiva e social, é sempre imediatamente uma politica de interfaces...

Se quisermos estender radicalmente este tipo de abordagem ao tratamento das questões relacionadas ao complexo "promoçãosaúde-doença-cuidado”, devemos não apenas rever a separação ontológica sujeito-objeto, mas igualmente a separação corpo-técnica (nas quais se fundam boa parte das concepções biologicistas de saúde) e conceber a saúde como um estado global de equilíbrio instável de diversos elementos conectados: corpos, ações, sensações, sintomas, sinais, signos, técnicas, elementos naturais e dispositivos os mais variados, que se rearranjam continuamente, na busca de um estado de saúde que jamais se estabiliza. Ponto de equilíbrio móvel, fugidio: reinvenção permanente da (idéia de) saúde. No limite, as técnicas (de saúde) podem ser vistas como autênticas secreções do nosso corpo coletivo (Teixeira \& Costa, 2000), que operam como desvios, deslocamentos, passagens que difratam os fluxos à nossa volta, para produzir estados de bem viver (Serres, 1997). Ao fazê-lo, intermedeiam nossa relação com o mundo, com os outros, com nós mesmos, com o nosso corpo, com essa ou aquela função; alteram nossas percepções e acabam operando "espiritualmente" conosco, sendo co-intérpretes do nosso mundo. De fato, as tecnologias podem ser vistas como autênticas hermenêuticas.

De uma perspectiva pragmática radical, pode-se considerar que toda interpretação é, a rigor, uma (re)utilização do material lingüístico, mas também, inversamente, toda utilização é, no fundo, uma (re)interpretação de material prévio. É nesse sentido, antes de mais nada, que podemos entender as tecnologias toda e qualquer tecnologia! - como hermenêuticas. As técnicas, mesmo as mais modernas, são todas constituídas de bricolagem, reutilização e desvio (Lévy, 1993). As tecnologias "interpretam” os agenciamentos disponíveis, criando novos agenciamentos, heterogêneos ou não.

Contudo, ao lado desse entendimento mais genérico das técnicas como hermenêuticas, há um outro que diz respeito, especificamente, às tecnologias que afetam mais diretamente a nossa experiência corporal.

Numa série de conferências sobre o "enigma da saúde”, o filósofo alemão Hans Georg Gadamer (1996) faz reflexões que, a meu ver, iluminam meridianamente esta segunda perspectiva de unificação da hermenêutica com a práxis. Isso porque, seguindo os passos da tradição fenomenológica pós-Husserl, atribui importância nuclear à "experiência corporal”, conectando o conhecimento, a compreensão do mundo e, até certo ponto, a subjetividade, "ao modo como a experiência corporal está fenomenologicamente dada”. Ora, como já advoguei, as tecnologias todas que "secretamos" e com as quais passamos a viver de uma forma acoplada, modificam, em graus variáveis de profundidade, "o modo como a experiência corporal está fenomenologicamente dada”. Isso já bastaria para que as considerássemos todas, "tecnologias de conhecimento".

Numa de suas belas conferências, Gadamer cita Rainer Maria Rilke ("Oh life, life, remaining always outside”), quando este trata do movimento de afastamento do mundo exterior e de "internalização" (inwardization), 
que acompanha os estados de dor física intensa. Para os fins da nossa presente reflexão, o fundamental parece estar contido na indagação do filósofo que encerra a passagem: Que contribuição especificamente humana nós podemos dar a estes problemas quando, como médicos, estamos em posse de uma capacidade crescente de controle instrumental sobre o corpo?

Numa recente pesquisa sobre o parto, envolvendo obstetras, obstetrizes e parturientes, lembro-me de ouvir com freqüência um discurso em favor da analgesia no parto, que afirmava que, sem a dor, a parturiente "participa" mais do parto, pelo menos do que se passa "exteriormente"... Não se trata, no momento, de ser nem contra, nem a favor da analgesia no parto, mesmo porque, não seria essa a discussão adequada (o que realmente deveria estar sob julgamento e escolha é, por exemplo, de que modo a parturiente deseja "participar" do acontecimento, entre outras opções vivenciais que se dissimulam sob escolhas técnicas). Ocorre apenas que o exemplo me parece dos mais privilegiados para se fazer ver o modo como uma dada "tecnologia do corpo" participa do processo de conhecimento, podendo ser dita, nesse sentido, uma autêntica "tecnologia de conhecimento", condicionando (isto é, não exatamente determinando, mas pré-restringindo) as possibilidades de conhecimento do parto, com ou sem a técnica. Na realidade, a questão é ainda mais complexa, porque não se trata apenas da técnica reinterpretar aquele acontecimento na medida em que se escolhe utilizá-la. A simples existência da possibilidade técnica da analgesia durante o parto ressignifica completamente a "opção" pelo parto sem a técnica (com dor)... A técnica reinterpreta definitivamente o acontecimento e, dessa maneira, põe "travas de irreversibilidade" no tempo, que só passa agora numa direção: a da reinterpretação infinita da nossa existência.

Pois bem, já vimos que uma técnica co-interpreta o mundo, conosco, e que sua simples presença já é, em si, uma (re)interpretação do mundo. É de fundamental importância compreender essa co-atuação das técnicas no modo como experimentamos o mundo, já que o que está sempre em jogo, em última instância, é como interpretamos o mundo e o que fazemos com nossos corpos.

Porém, até aqui, os exemplos só examinaram os "efeitos" produzidos pelos agenciamentos tecnosemiológicos num plano que pode ser dito molecular, isto é, apenas se conside- rando as características "microfísicas" de um dispositivo técnico bem circunscrito e isolado, quando, talvez, só passemos a divisar claramente as grandes linhas de formação coletiva da subjetividade, avançando para planos mais molares, considerando não um ou outro dispositivo técnico isolado, mas as tecnologias de organização das grandes redes técnicas, o modo, enfim, como funcionam os grandes sistemas compósitos e heterogêneos de interfaces tecnosemiológicas, dos quais é exemplo privilegiado a grande rede de serviços voltados para a satisfação de necessidades básicas de saúde.

É justamente com este exemplo, dos mais pertinentes à atualidade do campo da saúde coletiva, que gostaria de encerrar esta intervenção, e através dele esclarecer mais algumas das reciprocidades que se estabelecem entre os processos coletivos de produção de subjetividade e a rede de agenciamentos tecnosemiológicos disponíveis.

Tomemos um serviço de atenção primária à saúde como uma rede de interfaces tecnosemiológicas. Dada a impossibilidade, no momento, de se proceder a uma descrição pormenorizada de todas suas características de interface, de suas principais propriedades de "condução", de toda a complexa rede de fluxos, passagens, desvios, bloqueios, parasitismos, amplificações, traduções, difrações, transportes (que refazem, sem cessar, algumas das linhas de interpretação coletiva da existência por uma comunidade humana), que corresponde a uma unidade de prestação de cuidados básicos de saúde, proponho-me a examinar um dispositivo parcial dessa rede, mas um dispositivo especial, visto que corresponde a uma espécie de protocolo geral de comunicação entre todos os elementos que compõem a rede: a atividade ou, melhor definindo, o conteúdo de atividade assistencial que passo a denominar de acolhimento-diálogo ou acolhimento dialogado.

Para maior brevidade e poder de síntese, recorro a uma representação gráfica (Figura 1): trata-se do fluxograma da rede técnica assistencial do Setor de Adultos do Centro de Saúde Escola Samuel B. Pessoa (Departamento de Medicina Preventiva da FMUSP), num dado momento de sua evolução (2000), que não nos interessará por suas especificidades, sendo tomado apenas por sua forma geral abstrata, como um caso de rede técnica assistencial de uma unidade básica de saúde, em que 
Figura 1

Fluxograma da rede técnica assistencial

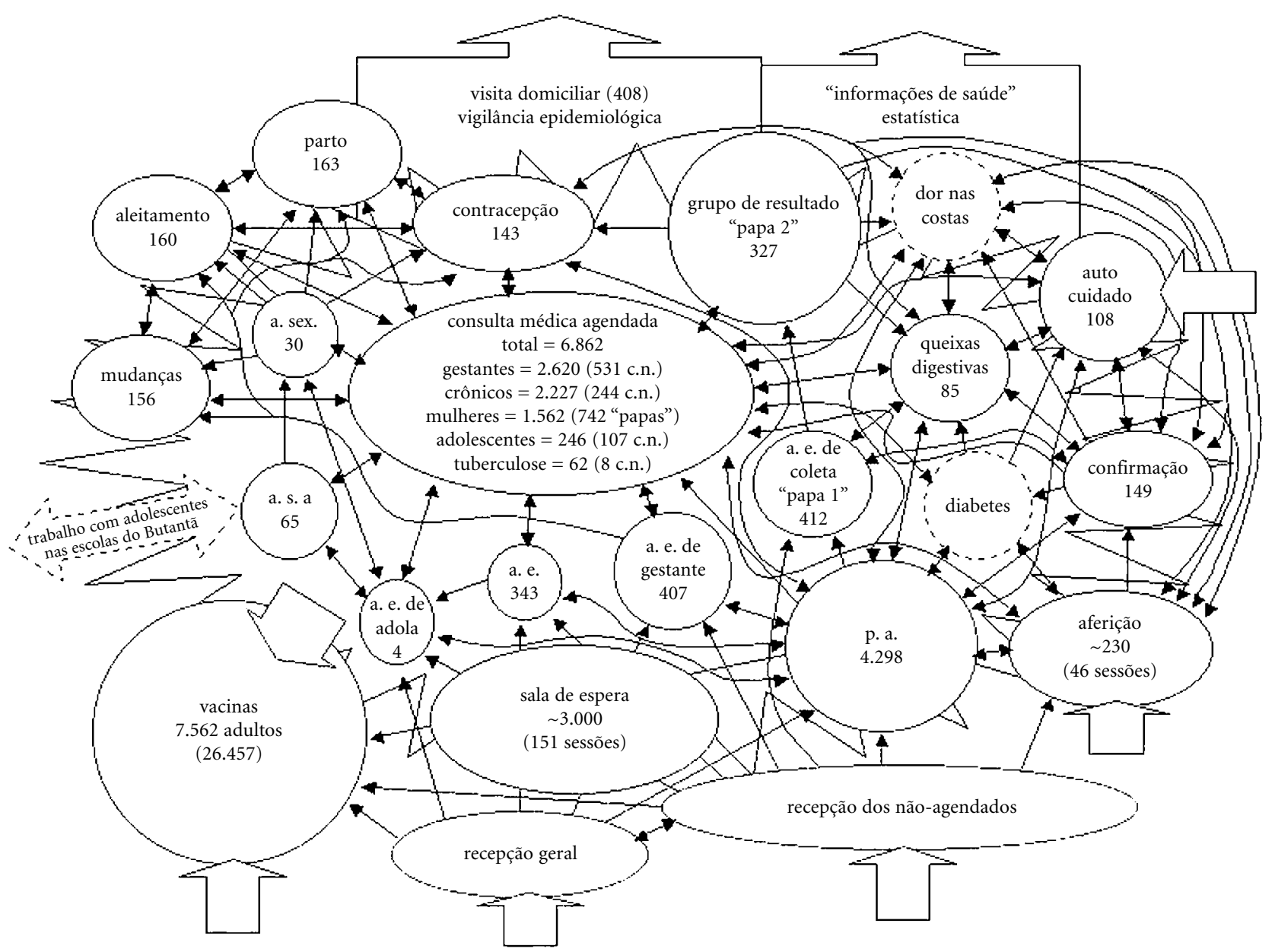

cada nó da rede corresponde a um "encontro" assistencial (individual ou grupal), um momento de "conversa" envolvendo uma série de atividades técnicas específicas.

Os diferentes "encontros" formalmente dispostos ao longo da trajetória de um usuário pelo serviço podem ser vistos como os momentos "sinápticos" de uma fluxografia organizacional em rede, cujos fluxos multidirecionais, multicombinatórios e flexíveis, interligam diferentes "módulos de atenção".

O funcionamento ótimo desta rede depende sobremaneira do desempenho da chamada atividade de recepção do usuário no serviço, entendida como espaço primordial de investigação/elaboração/negociação das necessida- des que podem vir a ser satisfeitas. Contudo, é mais do que evidente que essa atividade não se restringe a determinados espaços formalmente designados para a sua realização, proliferando por todos os encontros assistenciais que marcam a passagem de um usuário pelo serviço, já que nunca se cessa efetivamente de investigar/elaborar/negociar as necessidades que podem vir a ser satisfeitas pelo serviço. E é para que não se confunda esse já bem diferenciado conteúdo de atividade com o primeiro contato de um usuário com o serviço, que ele foi distintivamente denominado de acolhimento-diálogo. Ele desempenha um papel central no funcionamento da rede, ou, mais exatamente, um papel original. E original, não no 
sentido de primeiro encontro com o serviço, mas porque traduz a ação (passível de se realizar e que se realiza em qualquer dos encontros através do serviço e não apenas no primeiro encontro) que origina, que deflagra os diferentes possíveis trânsitos dos usuários pelo serviço, por seus diferentes "módulos de atenção". O acolhimento-diálogo, da perspectiva do desempenho global da rede, pode ser visto como uma espécie de distribuidor, de operador da distribuição, onipresente em todos os pontos da rede. Sendo tais encontros, momentos pautados pelo espírito do entendimento e da negociação permanente das necessidades a serem satisfeitas, é neles que se decide a trajetória "necessária" de cada usuário através do serviço.

Vê-se, aqui, a total adequação da metáfora da "sinapse", já que é nelas também que se decide o essencial da plasticidade desse sistema de "fluxos" que é o sistema nervoso. No nosso caso - de um sistema de "módulos de atenção à saúde" interligados -, a plasticidade favorece a diversidade de singularizações possíveis, já que a maior possibilidade de diferentes usuários realizarem diferentes combinatórias de "atenção" oferece uma margem maior de adaptabilidade a estruturas de necessidades bastante diversas, uma maior possibilidade de se diversificarem as modalidades de acoplamento estrutural ao sistema (Maturana \& Varela, 1998). A diversificação dos usos... Diferentes usuários, diferentes usos.

(Se houvesse mais espaço para continuar estes comentários, poderia ainda falar nas mudanças que se processam na "sensibilidade" de uma organização de atenção à saúde, que sofra uma tal evolução estrutural, nas suas novas potencialidades "perceptivas"... A biologia contemporânea também nos ensina que a percepção é inteiramente dependente da estrutura do organismo que percebe [Maturana \& Varela, 1998]. No nosso caso, isso pode significar, por exemplo, novas possibilidades de expressões de demandas... Novos ouvidos, novas vozes.)

Notemos que, até aqui, a descrição das características de interface do agenciamento tecnosemiológico representado pelo acolhimento-diálogo levou em conta apenas o que se poderia chamar de uma dimensão "procedural", isto é, de sua participação num agenciamento sistêmico, de seus efeitos na dinâmica da rede. Contudo, a descrição completa de suas propriedades de "condução", isto é, das caracte- rísticas "microfísicas" dessa interface, deve também levar em conta suas dimensões "declarativas". Só então aparece com maior clareza o modo como o acolhimento-diálogo define a dimensão pragmática do encontro, os domínios de ação (emoções), de significação (linguagem) e as utilizações possíveis da própria interface. Muito sumariamente, poderia descrevê-la considerando dois traços principais, já indicados nos dois componentes de sua designação: primeiramente, o acolhimento, que põe em relevo, antes de mais nada, o caráter de um acolhimento "moral" da pessoa (usuária do serviço) e suas demandas (que pode envolver, muitas vezes, um sofrimento importante). Esse gesto "receptivo" se faz acompanhar (dentro dos limites dados pelas circunstâncias concretas, como o bom senso faz supor) de um diálogo, que é o segundo traço descritivo desta interface. Este diálogo orienta-se pela busca de um maior "conhecimento" das necessidades de que o usuário se faz portador e dos modos de satisfazê-las, o que revela a, talvez, mais fina característica da operação de passagem promovida por esta interface e que está dada no pressuposto geral, a pautar todas as práticas de "conhecimento" que se dão no serviço (das atividades educativas stricto sensu a todas as formas de "conversa" em que se "pesquisa" alguma coisa), de que as nossas necessidades não nos são sempre imediatamente transparentes e nem jamais definitivamente definidas. O papel do acolhimento-diálogo na dinâmica organizacional deve ser entendido como o resultado de um encontro pautado por tais disposições "morais" e "cognitivas".

Creio que já expus o suficiente, até aqui, para compor um quadro geral que permita (re)pensarmos o "sujeito" (ou antes, a propriedade de ser sujeito: a subjetividade) e o papel desempenhado pelos "objetos" (entendidos como agenciamentos, como interfaces tecnosemiológicas) na trans-formação do nosso modo de ser sujeitos.

Vejo vantagens nesse modo de se colocar o problema da trans-formação do sujeito no campo da saúde, porque não é pequena a participação dos "objetos" que pomos no mundo nos processos coletivos de produção de subjetividade. Essa é, afinal, a definição de "trabalhadores sociais" que nos é proposta por Félix Guattari: todo aquele que atua de alguma maneira na produção de subjetividade,... trabalhando para o funcionamento desses processos na medida de suas possibilidades e dos agencia- 
mentos que consigam pôr para funcionar, tudo dependendo ... de sua capacidade de se articular com os agenciamentos que assumam sua responsabilidade no plano micropolítico.

E conclui: Mas, também, quem não trabatha na produção de subjetividade? (Guattari \& Rolnik, 1986).

Em meio a tantos discursos sobre o sujeito da ação, pretendi dar maior importância à ação que cria o sujeito (ou melhor, a ação de produzir a subjetividade). Ousaria afirmar que a produção de subjetividade talvez seja mesmo a ação por excelência, a práxis fundamental.

A essa máquina de produção de subjetividade eu oporia a idéia de que é possível desenvol- ver modos de subjetivação singulares, aquilo que poderíamos chamar de "processos de singularização": uma maneira de recusar todos esses modos de encodificação preestabelecidos, todos esses modos de manipulação e de telecomando, recusá-los para construir, de certa forma, modos de sensibilidade, modos de relação com o outro, modos de produção, modos de criatividade que produzam uma subjetividade singular. Uma singularização existencial que coincida com um desejo, com um gosto de viver, com uma vontade de construir o mundo no qual nos encontramos, com a instauração de dispositivos para mudar os tipos de sociedade, os tipos de valores que não são os nossos (Guattari \& Rolnik, 1986).

\section{Referências bibliográficas}

Bergson H 1997 (1ạ ed. 1927). Essai sur les donnés immédiates de la conscience. PUF, Paris, 184pp.

Chauí M 1997. Comentários. Subjetividades Contemporâneas (Instituto Sedes Sapientiae, São Paulo), ano $1(1)$ : 18-25.

Deleuze G 1988. Foucault. Brasiliense, São Paulo, 144pp.

Deleuze G \& Guattari F 1991. Qu'est-ce que la Philosophie? Minuit, Paris, 208pp.

Foucault M 1990. Tecnologías del yo. Paidós Ibérica, Barcelona, 150pp.

Gadamer HG 1996. The enigma of health. The art of heal ing in a scientific age. Stanford University Press, Stanford, 71-102 pp.

Guattari F \& Rolnik S 1986. Micropolitica-cartografias do desejo. Vozes, Petrópolis, 327pp.

Guattari F 1992. Caosmose-um novo paradigma estético. Ed. 34, Rio de Janeiro, 208pp.

Jaeger W 1995. Paidéia - a formação do homem grego. Martins Fontes, São Paulo, 1413pp.

Leroi-Gourhan A 1964. Le geste et la parole I: Technique et langage. Albin Michel, Paris, 324pp.

Lévy P 1993. As tecnologias da inteligência: o futuro do pensamento na era da informática. Ed. 34 , Rio de Janeiro, 203pp.

Lévy P 2000. L'intelligence collective et ses objets. http:// www.t0.or.at/levy/plevy.htm
Maturana H \& Varela F 1998. El árbol del conocimiento (14a ed.) Editorial Universitária, Santiago de Chile, $172 \mathrm{pp}$.

McLuhan M 1971. Os meios de comunicação como extensões do homem. Cultrix, São Paulo, 407pp.

Pelbart PP 1997. Subjetividades contemporâneas. Subjetividades Contemporâneas (Instituto Sedes Sapientiae, São Paulo), ano1 (1): 4-11.

Serres M 1995. A lenda dos anjos. Aleph, São Paulo, 302 pp.

Serres M 1997. Le parasite. Hachette, Paris, 461pp.

Silva A 1947. Alcorão (nunca publicado). In Ferraz MC (org.) 2000. Agostinho da Silva - depoimentos, textos, aquarelas e fotos. Instituto Lina Bo Bardi, São Paulo (mimeo).

Simondon G 1989. Du mode d'existence des objets techniques. Aubier, Paris, 161pp.

Spinoza B 1998. Ética. Alianza, Madri, 429pp.

Teixeira RR \& Costa R 2000. Novas tecnologias e sociedade pedagógica - uma conversa com Michel Serres. Interface - Comunicação, Saúde, Educação 4(6): 129-142.

Teixeira C 2000. Novas formas de organização. VI Congresso Brasileiro de Saúde Coletiva, Boletim no 2, p. 3 . 